\title{
Blended learning opportunities: skills for working with primary sources
}

\author{
Zoë Enstone \\ York St. John University, UK
}

Keywords: foundation year; blended learning; interdisciplinary; information literacy; object-based learning; primary sources; transition to university; academic skills.

\section{The challenge}

The Liberal Arts Foundation Year is an interdisciplinary programme that includes integrated academic skills development throughout. The complexities of both widening participation and interdisciplinary provision are well documented (e.g., Warren, 2002; Jones and Lau, 2010; Park and Son, 2010; Enstone and Newman, 2015; Abegglen, Burns and Sinfield, 2019) and the transition to university for Foundation Year learners can be especially difficult (Chivers, 2019). To support this transitional process and to develop key information literacy skills, the programme incorporates source skills for both critical or secondary reading in relation to working with novels, data, maps, historic documents, and other primary sources students might encounter in their varied subjects. This exploration enables the development of practical skills and critical approaches through a wider consideration of the nature of academic study, addressing aspects such as access and the focus of these resources in terms of inequalities and social issues in production, transmission, and reception in the past and present. The value of this content draws on the well-documented importance of information literacy within higher education provision (Shapiro and Hughes, 1996; Johnston and Webber, 2003; Wang, 2007). The programme also explores and challenges pre-conceived notions of the boundaries of subject disciplines, an issue important to the development of interdisciplinary provision (Brewer, 1999).

This provision includes a session at York Explore Archive, to consider the implications and use of archival sources, building on well-established connections between the approaches 
involved in effective information literacy provision and the hands-on nature of archives (Carini, 2016; Jarosz and Kutay, 2017), drawing on broader approaches from object-based learning (Chatterjee et al., 2015) and the disciplinary complexities of material culture (Hicks and Beaudry, 2010). This year's restrictions meant that we were unable to visit the archive in person which necessitated a reconsideration of how these key approaches and issues could be supported in a blended delivery, an issue faced by other practitioners in the delivery of object-based learning (Sheehy et al., 2021). The key issue was the need to engage students with interdisciplinary approaches to object-based learning and information literacy when the objects themselves and a discursive in-person format were not available. Without this intervention, students would have missed a key developmental element of information literacy, which is central to their academic advancement.

\section{The response}

There are many complex issues to consider in the shift to online provision for information literacy and skills development (Tang and Chaw, 2016; Weightman et al., 2017; Boyle et al., 2019; Fola-Adebayo, 2019; Nikou and Aavakare, 2021), and we were keen to ensure that there was a combination of individual and group, synchronous and asynchronous and, as part of a blended delivery model, integrated on-campus and online, sessions as well as a supporting website (https://zenstone9.wixsite.com/primarysources). One of the immediate advantages was flexible pathways within the resources; the website included a short video for each subject area explaining what students might explore within the discipline to dispel misconceptions and prompt engagement with the range of training available. This was interwoven with a choice of on-campus workshops in critical skills for different source types. This built to a virtual visit to the archives, again facilitated through the website and was framed through content on the nature of archives and a task identifying aspects of archives in their subject area. The scope of the website meant that each student was able to find their own route within the content through the utility of the design of the interactive materials. The second part of the visit was an exploration of materials provided and contextualised by York Explore Archive and the collaborative creation of a resource for the students to provide their own responses to the materials and reflect on the contributions of others. This was run at a designated time to facilitate time for questions and build a sense of group engagement with the content, but there was also scope for students to explore different aspects of the archival material and website beyond 
this. Students responded really positively to the virtual visit (and the content more generally), with comments on the visit noting that it was enjoyable and that it prompted further consideration of the content and materials beyond the class.

\section{Recommendations}

The shift to including online materials epitomised a blended learning approach, both in relation to the traditional definition of blended learning as a combination of the physical and digital (Allan, 2007), but also in the blend of discipline areas and in the combination of synchronous and asynchronous components. This has raised key questions about what can be taken forward from this for future iterations and, more broadly, the way in which this raises pedagogic and disciplinary questions, tensions, and possibilities. It also offered opportunities to consider the physicality of object-based learning and how this could be best considered in a virtual form. One of the key benefits of this project was that it enabled a more collaborative approach to the development and support of students and had unintended benefits in prompting a dialogue between disciplines. For instance, whereas in a subject like history or literature 'primary' was used to refer to a source that was first-hand in nature, for example a novel, photograph, etc., in geography, primary data was collected for a specific study and when used elsewhere would be considered secondary. These distinctions and discussions about disciplinary divergences, terminology, and approaches helped to ensure that resources and teaching were tailored to support students navigating these issues and would provide a good model for use elsewhere.

The creation of a set of asynchronous digital resources meant much greater flexibility for students; although this was a blended provision and the on-campus and live sections were crucial, being able to suggest that students explored their own routes and subject interests allowed for a collaborative approach to individualised pathways and bespoke skills development. For colleagues navigating the complexities of interdisciplinary provision, as well as the issues specific to WP, level 3, and subject-specific information literacy, a blended model of this nature might prove useful in navigating some of these diverse needs and concerns. 


\section{References}

Abegglen, S., Burns, T. and Sinfield, S. (2019) 'It's learning development, Jim - but not as we know it: academic literacies in third space', Journal of Learning Development in Higher Education, Issue 15, November, pp.1-19.

https://doi.org/10.47408/jldhe.v0i15.500.

Allan, B. (2007) Blended learning: tools for teaching and training. London: Facet. https://doi.org/10.29085/9781856047845,

Boyle, J., Ramsay, S. and Struan, A. (2019) 'The academic writing skills programme: a model for technology-enhanced, blended delivery of an academic writing programme', Journal of University Teaching \& Learning Practice, 16(4), pp.1-12.

Brewer, G. D. (1999) 'The challenges of interdisciplinarity’, Policy Sciences, 32, pp.327337. https://doi.org/10.1023/A:1004706019826.

Carini, P. (2016) 'Information literacy for archives and special collections: defining outcomes', portal: Libraries and the Academy, 16(1), pp.191-206. https://doi.org/10.1353/PLA.2016.0006.

Chatterjee, H. J., Hannan, L. and Thomson, L. (2015) 'An introduction to object-based learning and multisensory engagement', in Chatterjee, H. J. and Hannan, L. (eds.) Engaging the senses: object-based learning in higher education. London: Routledge, pp.1-20. https://doi.org/10.4324/9781315579641.

Chivers, E. (2019) 'The trials and tribulations of transition into foundation year study', Journal of the Foundation Year Network, 2, pp.69-78.

Enstone, Z. and Newman, M. (2015) 'Forming firm foundations: integrating interdisciplinarity in the arts and humanities', in Fraser, L and Mas Giralt, R. (eds.) It's all adult education: Proceedings of 44th Annual Conference. Leeds: Lifelong Learning Centre, University of Leeds, in conjunction with the Standing Conference on Teaching and Research in the Education of Adults, pp.153-159. 
Fola-Adebayo, T. J. (2019) 'Perceptions of undergraduates on the relationship between exposure to blended learning and online critical literacy skills', Reading \& Writing, 10(1), pp.1-9. https://doi.org/10.4102/rw.v10i1.200.

Hicks, D. and Beaudry, M. C. (2010) 'Introduction: material culture studies: a reactionary view', in Hicks, D. and Beaudry, M. C. (eds.) The Oxford handbook of material culture studies. Oxford: Oxford University Press, pp.1-24. https://doi.org/10.1093/oxfordhb/9780199218714.013.0001.

Jarosz, E. E. and Kutay, S. (2017) 'Guided resource inquiries: integrating archives into course learning and information literacy objectives', Communications in Information Literacy, 11(1), pp.204-220. https://doi.org/10.15760/comminfolit.2017.11.1.42.

Johnston, B. and Webber, S. (2003) 'Information literacy in higher education: a review and case study', Studies in Higher Education, 28(3), pp.335-352.

https://doi.org/10.1080/03075070309295.

Jones, N. and Lau, A. M. S. (2010) 'Blending learning: widening participation in higher education', Innovations in Education and Teaching International, 47(4), pp.405-416. https://doi.org/10.1080/14703297.2010.518424.

Nikou, S., Aavakare, M. (2021) 'An assessment of the interplay between literacy and digital technology in higher education', Education and Information Technologies, 26, pp.3893-3915. https://doi.org/10.1007/s10639-021-10451-0.

Park, J.-Y. and Son, J.-B. (2010) 'Transitioning toward transdisciplinary learning in a multidisciplinary environment', International Journal of Pedagogies and Learning, 6(1), pp.82-93. https://doi.org/10.5172/ijpl.6.1.82.

Shapiro, J. J. and Hughes, S. K. (1996) 'Information literacy as a liberal art: enlightenment proposals for a new curriculum', Educom Review, 31(2), np.

Sheehy, B., Sandstrom, M. and Heeg, J. (2021) 'Coming together through object-based learning in a pandemic', The Councilor: A Journal of the Social studies, 82(1), np. 
Tang, C. M. and Chaw, L. Y. (2016) 'Digital literacy: a prerequisite for effective learning in a blended learning environment?', Electronic Journal of e-Learning, 14(1), pp.54-65.

Wang, L. (2007) 'Sociocultural learning theories and information literacy teaching activities in higher education', Reference \& User Services Quarterly, 47(2), pp.149-158. https://doi.org/10.5860/rusq.47n2.149.

Warren, D. (2002) 'Curriculum design in a context of widening participation in higher education', Arts and Humanities in Higher Education, 1(1), pp.85-99. https://doi.org/10.1177/1474022202001001007.

Weightman, A., Farnell, D., Morris, D., Strange, H. and Hallam, G. (2017) 'A systematic review of information literacy programs in higher education: effects of face-to-face, online, and blended formats on student skills and views', Evidence Based Library and Information Practice, 12(3), pp.20-55. https://doi.org/10.18438/B86W90.

\section{Author details}

Zoë Enstone is a Senior Lecturer in Liberal Arts at York St. John University and Senior Fellow of the Higher Education Academy. She leads the Liberal Arts programme and is also Learning and Teaching Lead for the School of Humanities. 